\title{
A Proposed Return-to-Ride Protocol for United States Jockeys Following Concussion
}

Carolina Quintana, PhD, ATC*; Kimberly I. Tumlin, PhD, MS, MPH†; Matthew C. Hoch, PhD, ATC $\dagger$; Nicholas R. Heebner, PhD, ATC $\dagger$; Bianca L. Grimshaw $\ddagger$ MS, ATC, OTC; Carl G. Mattacola, PhD, ATC**

*California State University, Fresno, Fresno, CA; †University of Kentucky, Lexington, KY; †University of Louisville Health Sports Medicine Institute, Louisville, KY; **University of North Carolina Greensboro, Greensboro, NC

\begin{abstract}
Professional horse racing jockeys participate in a high-risk sport, however there is limited research and policies regarding welfare and safety. Despite the high incidence and risk of concussions, there are not standardized protocols for returning these unique athletes to participation following concussion. A return-to-ride concussion protocol for thoroughbred horse racing athletes must take into account the unique considerations and practices of the sport. Current concussion management strategies suggest removal from riding and activity when a concussion is suspected. This is followed by further evaluation for diagnosis, a period of both cognitive and physical rest before a gradual return-toactivity prior to full medical clearance and a return to previous levels of activity and competition. The proposed protocol follows suggested strategies while tailoring the graduated return-to-activity to meet the needs of the US jockey population. This protocol may be used following injury to ensure an adequate recovery and safe return-to-activity and is outlined such that it can be followed by an individual athlete and provides descriptions for each activity and stage.
\end{abstract}

\section{Key Phrases}

Concussion; policy and procedure development; risk management and mitigation

\section{Correspondence}

Dr. Carolina Quintana Department of Kinesiology, California State University, Fresno, 5275 N. Campus Dr. M/S SG28

Fresno, CA 93740-8018.

E-mail: carolinaquintana@mail.fresnostate.edu

Twitter: @cquintanaatc

\section{Full Citation}

Quiutana C, Tumlin KI, Hoch MC, Heebner NR, Grinshaw BL, Mattacola CG. A proposed return-to-ride protocol for United States jockeys following concussion. Clin Pract Athl Train. $2021 ; 4(3): 17-27$.

https://doi.org/10.31622/2020/0004.3.4.

Submitted: February 25, 2021 Accepted: June 15, 2021

\section{INTRODUCTION}

Concussions have been cited as one of the most frequently occurring injuries in professional horse racing jockeys around the world.1,2 The Centers for Disease Control and Prevention defines a concussion as a type of traumatic brain injury (TBI) that is "caused by a bump, blow, or jolt to the head or by a hit to the body that causes the head and brain to move rapidly back and forth." 3 These injuries may result in a disruption of brain function including, but not limited to, loss of consciousness, memory loss, disorientation or confusion, and other functional deficits. ${ }^{4}$ It is well documented that the majority of injuries that jockeys sustain are a result of falls. ${ }^{1,2,5-11}$ Hitchens et. al. reported that of 360 reported falls during thoroughbred races, 184 injuries occurred indicating that $51 \%$ of falls resulted in injury. ${ }^{8}$ Additionally there were 1.99 falls reported per 1000 rides. $^{8}$ Concussions have represented a higher percentage of overall injuries in jockeys, as high as $13 \%$ in a four month time frame. ${ }^{10}$ Despite concussions representing a large proportion of injuries in jockeys very few policies and procedures are in place throughout the United States that require adequate documentation and record keeping surrounding this type of injury. As a result, the actual injury prevalence in this population remains undocumented. While it is clear there is both high risk and high incidence of these injuries, there are many factors specific to horse racing that need to be considered to impose the healthcare of jockeys.

Despite concussion being recognized as the most frequently occurring injury among jockeys, ${ }^{10,12}$ it has been reported in other sports that many head injuries go unrecognized, unreported, or undiagnosed, 13,14 therefore, it may be assumed that the estimates of the true number of racingrelated concussions are skewed or inaccurate. Reasons for not reporting concussions have been attributed to overall lack of access to medical 
professionals when an injury occurs, education regarding the injury risks, signs and symptoms, and sport-specific guidelines to return athletes to competition, the importance of treating these injuries appropriately. ${ }^{15}$ Recent literature from amateur and professional jockeys in Ireland also cite not considering a concussion to be serious, risk of losing a ride and therefore wages, and seeing the injury as a sign of weakness as additional reasons riders would not report a concussion and continue to ride. 16 The overwhelming lack of resources and education is especially apparent within the thoroughbred horse racing industry in the United States, as availability of onsite healthcare or resources at the racetrack is inconsistent and procedures used are not universally adopted. While other racing jurisdictions such as the British Horseracing Authority have implemented concussion protocols to manage concussions, 17 the United States has yet to implement or adopt protocols unique to the needs of riders in the United States.

In the United States, equestrian sports remain some of the only organized competitive activities that have not adopted national and comprehensive concussion management protocols or guidelines. While significant progress has been made to improve the management of concussions in horse racing and other equestrian sports, ${ }^{18-24} a$ gap continues to exist on contextuallyappropriate return-to-sport protocols. ${ }^{25}$ At this time, there is no consistent healthcare management or practices from track to track across the country. Additionally, there is a lack of standardized baseline concussion protocols and tracks and jurisdictions are left to make their own protocols, policies and procedures. While information may be circulated or provided, there are not standard guidelines or recommendations for the racing community.

Non-racing equestrian ${ }^{24}$ and professional rodeo have established concussion return-to-ride guidelines, ${ }^{23}$ but these do not consider the unique qualities of time pressures to resume racing, need for comprehensive medical oversight, and lack of training protocol for personnel on concussion management at all racing tracks. Therefore, the uniqueness of thoroughbred horse racing and the occupational demands placed upon race-riding jockeys warrant contextually appropriate protocols for concussion management in this sport that can be implemented regardless of resources or healthcare personnel available.

Generic return-to-sport guidelines have been developed by groups such as the Concussion in Sport Group 26 and the American Academy of Neurology; ${ }^{27}$ however, these guidelines do not reflect the sport-specific needs of the United States jockey population to ensure the best standard of care and practice. Despite clear need for concussion education for jockeys, the lack of a systems-wide support to decrease perceived negative connotations of addressing concussion still exists. ${ }^{16}$ As such, addressing the need for a jockey-specific return-to-ride guideline following concussion injury which considers the racing environment, physiological demands, and potential health disparities is not only necessitated, but required to advance safety in these athletes. Therefore, the proposed return-toride progression protocol is based on other sport protocols but is specific to the needs and demands of race riding. The proposed protocol is similar to Wicklund et al. ${ }^{23}$ who created a protocol for the rodeo athlete, and Serrano and Wu's ${ }^{24}$ management policy for Collegiate Hunter/Jumper Equestrian Athletes, is an adaptation of the widely accepted graduated return-to-sport strategy suggested by the Concussion in Sport Group, ${ }^{26}$. It must be acknowledged that while concussion management is being addressed in international racing jurisdictions the diversity of needs and practices within US horse racing sport necessitates the proposed protocol. 


\section{CURRENT MODEL}

\section{Protocol Description}

Existing standards for horse racing injury management include having at least one medical professional at a racetrack during both morning workouts and live racing. The medical professional, such as a physician or licensed medical professional, must be trained to diagnose concussion and clear riders for additional riding post-fall. ${ }^{28}$ Although the sport lags behind other organizations in the development and practice of concussion management guidelines, it is important that any suggested protocols stay current with recommendations in other sports. Thus, current recommendations are moving away from the idea of complete rest, dark rooms and isolation from stimulation, the suggested protocol promotes an active recovery and expedites exposure to physical, mental, and social activity. ${ }^{29,30}$ To create a riding specific protocol, existing live racing data were analyzed and compared to data collected using a riding simulator. ${ }^{31}$ A Racewood Racing Simulator (Racewood Equestrian Simulators, Cheshire, UK) was utilized so that heart rate data of race-riders of various professional levels could be monitored in simulated racing conditions. ${ }^{31}$ Utilizing a racehorse simulator and removing the live horse provides a much safer environment for the rider to increase physical exertion and gradually return-to-riding without the risk of injury from a fall from an unpredictable event. The proposed protocol focuses on a gradual increase in intensity as monitored by percent heart rate, and exercise demands (repetitions) until sportspecific intensity has been reached. Mean heart rates measure during live and simulated racing were used to set parameters for each stage. One standard deviation above and below the target heart rates, derived from the mean heart rates, were identified and compared to previously set standards for validity for each stage. ${ }^{26}$
Simulated races were used to mimic a physical situation close to what a jockey would encounter in a live race. A previous study ${ }^{31}$ investigating heart rate during live and simulated rides demonstrated that although there is not a significant difference in peak heart rate between the two, there was a nearly $15 \%$ gap in achieved peak heart rate during the simulated ride when compared to the peak heart rate during live racing. Although horse simulators have not been compared to treadmill exercise, prior research indicating that heart rate at $80 \%$ of heart rate achieved at symptom exacerbation using the Buffalo Concussion Treadmill Test is an acceptable level. Given the work comparing live racing and simulation and the Buffalo Concussion Treadmill Test, ${ }^{32}$ it is concluded that a goal of achieving $85 \%$ of the maximum peak heart rate during live racing was selected as the final exertion stage for simulated riding in our return protocol is appropriate to prevent symptom exacerbation. ${ }^{31}$ From there, a reversed approach was then taken to graduate heart rates from the $85 \%$ maximum; equivalent to return of racing while mounted on a live horse. Through this process, average peak heart rate during live racing was used to create a range of target heart rates for each stage moving at $10 \%$ from the prior state. The suggested heart rate zones are expected to be achieved and maintained during an exercise bout lasting at least two minutes, the duration of an average horse race in the United States. This step also mimics the intensity and timing of workouts and training bouts on the horse, as workout lengths typically range between 2 to 8 furlongs while race lengths range from 5 to 12 furlongs. Furthermore, use of peak heart rate to inform stage thresholds is contextually simplistic to use and implement in the jockey community, thus enhancing a culture of acceptance during postconcussion recovery (Table 1). This approach is advantageous to ensuring reduction of risk moving through the first three stages of the protocol 
Table 1: Proposed Return-to-Ride Protocol by Activity Stage and with Target Heart Rate Progression

\begin{tabular}{lcc} 
Objective & $\begin{array}{c}\text { Target Heart Rate } \\
\text { Zone }\end{array}$ & Criteria to Progress to Next Stage \\
\hline $\begin{array}{l}\text { Stage 1: Light Activity } \\
\begin{array}{l}\text { Gradually reintroduce light activity and activities } \\
\text { of daily living that do not aggravate symptoms } \\
\text { or place individual at risk for secondary impact } \\
\text { or fall }\end{array}\end{array} \quad \leq 100 \mathrm{BPM}$ & $\begin{array}{c}\text { Participate in activities in daily } \\
\text { living without an increase in } \\
\text { symptoms for 24 hours }\end{array}$ \\
\hline
\end{tabular}

\section{Stage 2: Light Aerobic Activity}

Introduce light aerobic cardiovascular effort while

minimizing secondary fall or impact by doing

activities away from a horse that do not present

a high risk

98-11 11 BPM
OR
$\leq 60-70 \%$ of
maximum heart rate

Maintenance of heart rate within

target heart rate zone for ten, twominute simulated rides on a race

Stage 3: Sport-Specific Exercise

Work to increase heart rate to $75 \%$ of maximum
112-151 bpm
OR

heart rate as the goal of the cardiovascular

fitness levels in ways other than riding a live

horse, incorporating race horse simulator

Stage 4: High Intensity Sport-Specific Exercise

Simulated rides should be continued with the

intention of increased heart rate greater than

$85 \%$ of the peak heart rate experienced during

live racing.

Stage 5: Return to Live Horse

Reintroduce live horse and begin to restore riding performance and confidence $\leq 75 \%$ of maximum heart rate

151-171 BPM OR

$\leq 85 \%$ of maximum heart rate

151-171 BPM or above
Maintenance of heart rate within target heart rate zone for ten, twominute simulated rides on a race horse simulator

\section{Stage 6: Full Participation}

Return to race related activities and full

competition

$B P M=$ beats per minutes

ensuring the jockey has reached cardiovascular exertion without exacerbating prior injury.

As in the guidelines outlined by McCroy et al., ${ }^{26}$ if at any point during the return-to-ride graduated protocol the individual experiences a return or provocation of concussion symptoms, the athlete should return to the previous asymptomatic level and work to progress from that stage forward after a 24-hour period without concussion-related symptoms at that level. Monitoring the progression of the protocol and advancing riders to the next step should be done by licensed healthcare professionals. Athletic trainers are keenly suited for this role due to their knowledge and experience managing these injuries. As an additional consideration, riders should strive to maintain good nutrition, hydration and sleep, to promote good health and recovery, such as those described in the American College of Sports Medicine Joint Position Statement: Nutrition and Athletic Performance. ${ }^{33}$

\section{Stage 1: Light Activity}

In Stage 1, the aim is to gradually reintroduce light activity that does not aggravate postconcussion symptoms (e.g., headache, dizziness, nausea). Riders should only participate Stage 1 once they have been deemed asymptomatic by a 
licensed healthcare professional. These activities may include activities of daily living that do not place the individual at risk for secondary injury or provocation of symptoms (e.g., walking, bathing, doing household chores). These activities should be initiated after a period of at least 24 hours of physical and cognitive rest. Encouraging the rider to stay involved in everyday activities outside of riding may promote motivation and positively affect mood and general emotional and mental well-being while they are unable to participate in riding. To graduate from Stage 1 the rider, at a minimum, should be able to participate in activities of daily living without an increase in symptoms but should be guided by a clinician.

\section{Stage 2: Light Aerobic Activity}

Stage 2 of the progression places an emphasis on light aerobic cardiovascular activity while minimizing secondary fall or impact by doing activities away from a horse that do not present a high fall risk. This stage should begin 24-hours after the successful completion of Stage 1 with no return of symptoms. Riders gradually begin light aerobic activities that may be done at the racetrack, in a gym or anywhere they may be able to walk, jog or complete other light activities with minimal risk of falling or impact to the head. Successful completion of this stage will depend heavily on whether or not the increased intensity of activity causes a return of symptoms. Riders should be monitored before, during, and following activity to detect any potential symptom return. The intensity and duration of light aerobic activity in Stage 2 should demonstrate a marked increase from Stage 1 before progressing to the next stage. Additionally, progression should only occur when riders are able to complete the activity without complications or a provocation of symptoms. Graduation from this stage requires the maintenance of heart rate within the target heart rate zone (98- 111 beats per minute or $\leq 65 \%$ of maximum heart rate) for ten, two- minute simulated rides on a racehorse simulator. If the rider is able to complete these exercise bouts without a provocation of symptoms, as monitored by a licensed medical professional who is managing their care, they may move onto Stage 3.

\section{Stage 3: Sport-Specific Exercise}

The goal of Stage 3 is to have the rider increase their heart rate to $75 \%$ of maximum heart rate in ways other than riding a live horse. Based on previously reported physiological heart rate data during live racing, ${ }^{31}$ increasing heart rate to a percentage $(<75 \%)$ of the jockey's maximum heart rate is appropriate in this stage. As indicated previously, this value is based on the overall target heart rate of $85 \%$ of the jockey's maximum heart rate ${ }^{31}$ and working backwards to create attainable and meaningful heart rate targets and based on prior research indicating that exercise intolerance post-concussion is achieved at $85-90 \%$ of heart rate. ${ }^{32}$ Use of a self-propelled racehorse simulator like the Racewood RaceTrainer RT (Racewood LTD, Tarporley, England) (Figure 1), Equicizer (Equicizer, Norwalk, OH), or fully mechanized and computer integrated simulator such as MK10 RACEHORSE SIMULATOR (Racewood LTD) is frequently part of United States jockeys' training regime and is appropriate in this stage (Figure 1).

On these simulators, arm motions are increased during practices to simulate "chasing" or motivation of the live horse. Arm cranking in other port results in higher heart rate, heart rate variability, increase in sympathetic outflow. $34-36$ If a racehorse simulator is not available for any or all of the steps in the return-to-ride progression, other activities with a cardiac demand, with low risk of reinjury, i.e. elliptical or treadmill, may be utilized to achieve the target heart rate. 


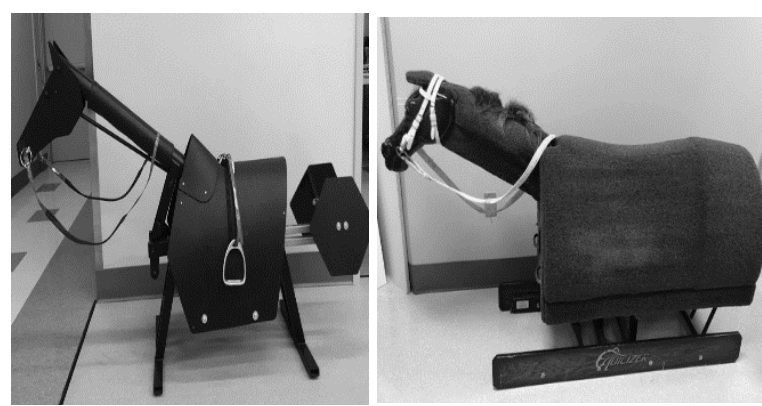

Figure 1. Examples of Racehorse Simulators

Utilizing a racehorse simulator allows the ability to mimic racing through a sport-specific activity with limited risk of secondary impact or falls. Additionally, to better prepare for the return-toriding and racing, riders should consider incorporating dynamic balance activities into their exercise routines. Dynamic balance is a crucial component to riding and balance dysfunction is a common consequence of concussion. The BOSU ${ }^{\circledR}$ PRO Balance Trainer provides a method for training balance and stability and can be adapted to create a sport-specific training environment. Riders can progress through basic balance exercises such as single leg stance to holding a low squat or "riding stance" on a foam pad and progress to using the BOSU ${ }^{\circledR}$ PRO Balance Trainer for longer periods of time, mimicking a race.

In order to warrant progression to the next step, riders should be able to attain $75 \%$ of their maximum heart rate and maintain a heart rate within the zone using a racehorse simulator for ten, two-minute bouts. Additionally, the rider should be able to demonstrate acceptable levels of balance. Maintaining upright balance on the BOSU ${ }^{\circledR}$ PRO Balance Trainer for a minute and a half to two minutes would provide evidence of acceptable balance as the time would be equivalent to the duration of most thoroughbred horse races (Figure 2). This can be done in double limb standing stance and progressing in difficulty from standing, to squatting to in a crouching position, closer mimicking the riding stance with both feet on the flat side of the BOSU ${ }^{\circledR}$ PRO Balance Trainer. Added perturbations to the balancing riding stance would better assess dynamic balance while also replicating the outside influences on riding during live races. Similarly to the simulated ride, this should be completed a total of ten rounds, to better demonstrate the ability to maintain repeated exercise bouts. In addition, light aerobic activity may be completed in Stage 3 to increase endurance and maintain a baseline level of fitness.

\section{Stage 4: High Intensity Sport-Specific Exercise}

During the Stage 4, simulated rides should continue with the intention of increasing the heart rate to greater than $85 \%$ of the peak heart rate experienced during live racing. When returning athletes from concussions, increasing cardiovascular demands without symptom provocation continues to be the standard. Thus, more challenging and sports-specific training should be added such as decision-making tasks during a simulated ride, challenges of reaction time, and continued balance training/exercises while also increasing the heart rate. This may be done through the implementation of cognitive tasks that require the rider to provide a "correct"

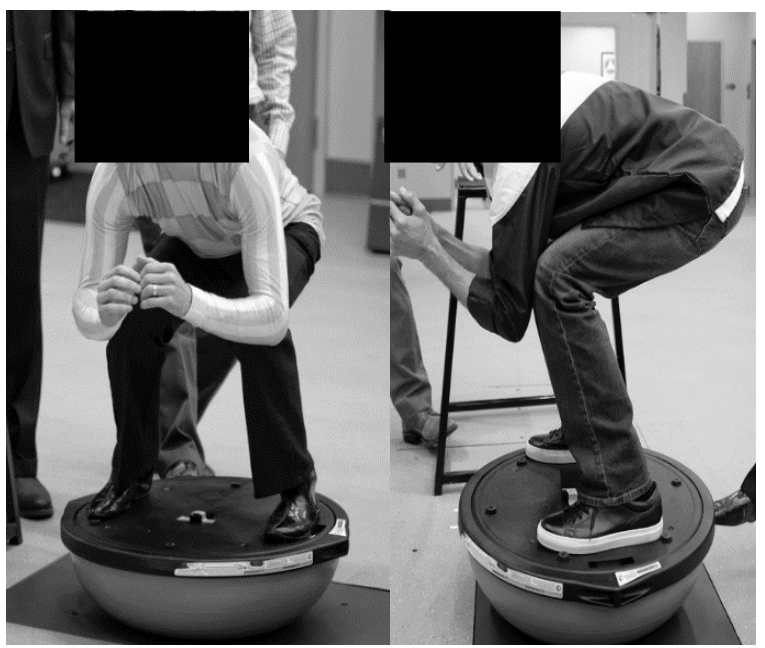

Figure 2. $B O S U^{\circledR}$ PRO Balance Trainer Balance Exercise 
answer based on a provided stimulus or catching a ball or object thrown that they are unable to anticipate at varied speeds. Successful progression from Stage 4 should only occur if the rider is able to maintain the heart rate zone during another set of 2-minute riding bouts without symptoms.

\section{Stage 5: Return to Live Horse}

Following medical clearance to return-to-riding by an appropriate licensed medical professional (i.e., MD, DO, ATs, the return to live horse stage is the first stage in which the rider is reintroduced to the live horse. Before returning to full race riding, the rider should gradually progress from breezing horses to breaking from the gate before competing in a full race, over the course of consecutive days. Breezing is the term used for a "workout in which a horse is easily running under a hold without encouragement from the rider." 37 At this point, there is not a limit on the activity. It is important that the rider has restored confidence on the horse and functional skills before returning to pre-injury activity levels. This may be completed during morning workouts or at a training center, galloping and/or breezing horses. Track conditions listed at least as "good" for dirt or "firm" for turf are recommended. Through a gradual reintroduction to race riding, without a return of symptoms and regained confidence, riders may return to full competition.

\section{Stage 6: Full Participation}

When athletes successfully complete the reintroduction to race riding without a provocation of symptoms or other unforeseen issues, it is then safe for the jockey to return to race related activities and participation in full races. In accordance with The Association of Racing Commissioners International's Model Rules of Racing, ${ }^{28}$ the jockey must be cleared by a physician or licensed medical professional before returning to racing.

\section{DISCUSSION}

Policies that protect the jockey profession are minimal in the United States, including the lack of standardized protocols to manage injury. Concussion experts and groups have developed guidelines and protocols to return athletes to sport following concussion; however, these guidelines do not provide directed goals based on the physiological and biomechanical demands and unique nature of the sport of horse racing. The proposed protocol provides specific heart rate metrics and guidance on progressive activities to achieve a gradual, safe return-to-sport for horse racing jockeys. Professional horse racing is a highrisk sport with unique considerations and physical demands for its athletes. With high inherent risk of injury, and documented high rates of concussions, it is imperative that professional jockeys have guidelines designed for athletes to achieve high levels of athletic activity necessary to safely compete and perform at pre-injury levels. Injury management protocols not only protect the injured rider but improve the overall safety of the other horses and riders by removing riders that are not fit to ride from the field. These recommendations are consistent with the protocols of major sports organizations such as the National Football League (NFL), National Collegiate Athletic Association (NCAA), and other professional and collegiate sports. This alignment is important in making strides towards recognition that the jockey has the access to and similar protections as other sport's athletes.

Previous return-to-sport progressions included graduated progressions, increasing exercise intensity, incorporating sports-specific exercise to gradually and safely return athletes to sport. Metrics that are easy-to-understand and implement into practice will facilitate compliance to various post-injury policies for United States jockeys. Intentionally, this protocol was designed to build on existing protocols and consider athletic 
performance requirements. Progression through the protocol, similar to other return-to sport protocols, includes a period of rest, as suggested, immediately following concussion injury, monitoring of self-reported symptoms, and the use of other assessment tools to objectively assess function. ${ }^{26}$ Progression through the proposed protocol should be monitored closely and managed by a healthcare professional such as athletic trainer or sports medicine physician; adoption of this protocol highlights the importance of having these professionals available to jockeys during workouts and live racing. The presence of an athletic trainer at the racetrack presents many benefits for the racing community including the management of concussions and safely returning jockeys to sport. The versatility, skill and training position athletic trainers to be ideal and dynamic healthcare professionals suited to serve the horse racing community.

This protocol sets the groundwork for putting United States jockey health at the forefront of return-to-sport considerations, limiting the risk of premature return-to-participation, and providing benchmarks through progression as well as exercises specific to the population. Current literature on NCAA athletes suggests the time to return to play and time that to the symptom free window have increased over time. These data should be investigated in this population and kept in mind for clinical decision making moving forward. ${ }^{38}$ Return-to-sport guidelines are only one piece to the concussion management puzzle and should be backed by standards and accrediting criteria to ensure proper implementation and practices. Additionally, this protocol does not minimize the risk of concussion injury in sport, but rather provides an opportunity for improved clinical practice following concussion injury.

In this protocol, heart rate as a measure of physiological demands was evaluated in racehorse jockeys during live racing in a cohort of professional jockeys, predominately male $(n=29$, 2 female). ${ }^{31}$ Peak heart rate was documented at $187 \pm 11$ beats per minute with an overall average peak heart rate of $169 \pm 10$ beats per minute, demonstrating a high cardiovascular demand. ${ }^{31}$ These data support that in addition to resolution of injuries sustained in return-to-sport protocol, demonstration of high cardiovascular fitness is necessary for a safe return. Heart rate is integral to assess the brain's ability to maintain pressure changes due to increased activity, without a return or exacerbation of symptoms. Exercise post-concussion is an effective strategy if heart rate is monitored to ensure that exacerbation of symptoms is not achieved. ${ }^{32,39} \mathrm{An}$ increase in symptoms may occur with an increased heart rate because as severity of brain injuries increases, the autonomic nervous and cardiovascular systems become increasingly uncoupled. 40 Therefore blood flow regulations and adaptations to the disruption from concussion may explain why symptoms reappear or worsen with physical exertion or other stressors that increase blood pressure. ${ }^{30}$

This protocol is the first of this kind specific to the sport of horse racing, however limitations are based on lack of data at the population level. Building on existing protocols from other sports, the recommendations for each stage are clearly linked to progression in cardiovascular exertion measured by heart rate. Despite being evidencebased on live heart rate collected during competition, the sample size is small and may not be representative of all jockeys by experience level and age. We did not control the impact of social behaviors; however the potential impact should not be overlooked. The impact of social behaviors on heart rate such as weight reduction methods including intentional dehydration will alter cardiovascular output. As such, this protocol sets guidelines for optimal performance, and individual health behaviors will need to be considered in use of the guidelines. Additionally, 
other factors may influence the recovery timeframe including the various concussion pathways such as vestibular involvement or sleep difficulties.

The recommended protocol meets many of the needs and fills current gaps in the thoroughbred horse racing industry and improves the safety and welfare of professional jockeys. However, the suggested protocol is not without limitations. While the authors have proposed a protocol that utilizes licensed medical professionals to monitor the progress through the stages and the safe returnto-riding, not all riders have access to the proposed level of healthcare. To better meet the needs of this unique population, racetracks should consider employing athletic trainers to provide quality healthcare to the riders and manage injuries. An additional limitation is the potential lack of access to a racehorse simulator as suggested throughout. Activities that place similar demands on the body such as running or riding a stationary bike may be used in a similar way to reach the target heartrate for each stage when a simulator is not available.

The suggested protocol serves as a starting point, continued efforts should work to improve and build on the work suggested to ensure the best possible protocols and practices in the sport. Future iterations should examine scores on neurocognitive tests, objective balance tests, vestibular and oculomotor tests, and mental health assessments to provide a more robust evaluation and data driven return to ride criteria.

\section{CLINICAL BOTTOM LINE}

Current concussion guidelines recommend sportspecific intensity through three stages of return-tosport following concussion. This research is important because it initiates the implementation of a graduated return-to-sport protocol, a comprehensive understanding of the recovery process, and intervention for a safe return-to-ride for professional jockeys. ${ }^{39}$ A riding simulator adds controlled, sport-specific exercise when returning a jockey to athletic performance that is based on the percentage of peak heart rate values previously established. These recommendations may also be suitable for other equine sports including but not limited to polo, show jumping, and eventing, but further evidence is necessary to establish maximal sport-specific exertion of these disciplines or other criteria that may be critical to clinical decision-making following concussion.

\section{REFERENCES}

1. Turner $M$, McCrory $P$, Halley $W$. Injuries in professional horse racing in Great Britain and the Republic of Ireland during 1992-2000. Br J Sports Med. 2002;36(6):403-409. https://dx.doi.org/10.1 136\%2Fbjsm.36.6.4 03.

2. McCrory $P$, Turner M, LeMasson B, Bodere C, Allemandou A. An analysis of injuries resulting from professional horse racing in France during 1991-2001: a comparison with injuries resulting from professional horse racing in Great Britain during 1992-2001. Br J Sports Med. 2006;40(7):614-618. https://doi.org/10.1136/bjsm.2006.02844 q.

3. Center for Disease Control and Prevention. Heads Up Brain Injury Basics. https://www.cdc.gov/headsup/basics/index .html. Published 2019. Updated February 12, 2019. Accessed September 9, 2019.

4. Laker SR. Epidemiology of concussion and mild traumatic brain injury. PM\&R. 2011 ;3:S354-S358. https://doi.org/10.1016/i.pmri.2011.07.01 7.

5. Cowley S, Bowman B, Lawrance M. Injuries in the Victorian thoroughbred racing industry. $\mathrm{Br}$ J Sports Med. 2007;41(10):639-643. https://dx.doi.org/10.1 136\%2Fbjsm.2006. 032888.

6. Foote C, Mclntosh A, V'Landys P, Bulloch K. Health and safety in Australian horse racing. Canberra, Australia: ACT. 2011. 
7. Rueda MAF, Halley WL, Gilchrist MD. Fall and injury incidence rates of jockeys while racing in Ireland, France and Britain. Injury. 2010;41(5):533-539. https://doi.org/10.1016/i.injury.2009.05.0 09.

8. 8. Hitchens $P L$, Hill $A E$, Stover SM. Jockey falls, injuries, and fatalities associated with thoroughbred and quarter horse racing in California, 2007-2011. Orthop J Sports Med 2013;1(1):1-7. https://doi.org/10.1 177\%2F23259671134 92625.

9. Oikawa M. The science of safety helmetssafety for helmets or safety for jockeys. Jpn Racing J. 2004;1 2(2):5-6.

10. Press JM, Davis PD, Wiesner SL, Heinemann A, Semik $P$, Addison RG. The national jockey injury study: an analysis of injuries to professional horse-racing jockeys. Clin J Sport Med. 1995;5(4):236-240.

11. Waller AE, Daniels JL, Weaver NL, Robinson P. Jockey injuries in the United States. JAMA. 2000;283(10):1326-1328. https://doi.org/10.1001/iama.283.10.132 b.

12. Cripps AE, Mattacola C. Professional thoroughbred jockey injuries: epidemiology, causations, and outcomes. I Athl Med. 2014;1:29-34.

13. Llewellyn T, Burdette GT, Joyner AB, Buckley TA. Concussion reporting rates at the conclusion of an intercollegiate athletic career. Clin J Sport Med. 2014;24(1):76-79. https://doi.org/10.1097/01.jsm.00004328 53.77520.3d.

14. Meehan WP, 3rd, Mannix RC, O'Brien MJ, Collins MW. The prevalence of undiagnosed concussions in athletes. Clin J Sport Med. 2013;23(5):339-342.

https://doi.org/10.1097/ism.0b013e31829 $1 \mathrm{~d} 3 \mathrm{~b} 3$.

15. Kerr ZY, Register-Mihalik JK, Marshall SW, Evenson KR, Mihalik JP, Guskiewicz KM. Disclosure and non-disclosure of concussion and concussion symptoms in athletes: review and application of the socio-ecological framework. Brain Inj. 2014;28(8):10091021. https://doi.org/10.3109/02699052.2014. 904049.

16. O'Connor S, Warrington G, Whelan G, McGoldrick A, Cullen S. Concussion history, reporting behaviors, attitudes, and knowledge in jockeys. Clin $J$ of Sport Med. 2020;30(6):578-584.

https://doi.org/10.1097/ism.00000000000 00658.

17. BHA enhances concussion management protocols. 2016. Available at https://www.britishhorseracing.com/press re leases/bha-enhances-concussionmanagement-protocols/.

18. Gulfstream jockeys complete baseline tests for new concussion protocol. 2018 Available at https://www.paulickreport.com/news/the$\mathrm{biz} /$ gulfstream-jockeys-complete-baselinetests-for-new-concussion-protocol/

19. CHRB proposes new regulations regarding jockey concussion protocols. 2019. Available at https://www.paulickreport.com/news/thebiz/chrb-proposes-new-regulations-

regarding-jockey-concussion-protocols

20. Jockeys undergoing more concussion tests as brain injury concerns increase. 2018. Available at https://www.wkyt.com/content/news/Jockey s-undergoing-more-concussion-tests-as-braininjury-concerns-increase-48 $1295221 \mathrm{html}$

21. Lief $E$. In the concussion research saddle, to protect jockeys. American Council on Science and Health. October 232017. https://www.acsh.org/news/2017/10/23/c oncussion-research-saddle-protect-jockeys12002

22. Keeneland initiates concussion protocol for jockeys beginning with fall meet. 2017. Available at https://www.keeneland.com/racing/keenela nd-initiates-concussion-protocol-jockeysbeginning-fall-meet

23. Wicklund A, Foster SD, Roy AA. Getting back on the horse: sport-specific return to play in rodeo athletes after concussion injury. Journal of athletic training. 2018;53(7):657-661. https://doi.org/10.4085/1062-6050-31017.

24. Serrano D, Wu V. Implementation of a novel return-to-ride concussion management policy 
for collegiate hunter/jumper equestrian athletes. Clin Prac in Athl Tr. 2020;3(2):1532. https://doi.org/10.31622/2020/0002.4.

25. Horse racing playing catch-up on jockey concussion protocol. The Associated Press; 2018.

26. McCrory P, Meeuwisse W, Dvorak J, et al. Consensus statement on concussion in sportthe 5th international conference on concussion in sport held in Berlin, October 2016. Br J Sports Med. 2017:bjsports-2017-097699. http://dx.doi.org/10.1136/bjsports-2017097699.

27. Giza C, Kutcher J, Ashwal S, et al. Summary of evidence-based guideline update: evaluation and management of concussion in sports report of the guideline development subcommittee of the American academy of neurology. Neurology. 2013;80(24):22502257.

https://dx.doi.org/10.1212\%2FWNL.0b01 $3 e 31828 d 57 d d$.

28. International TAORC. Model rules of racing In. ARCl-007-020 Facilities and Equiptment Vol $5 b, 102018: 2$.

29. Sufrinko AM, Kontos AP, Apps JN, et al. The effectiveness of prescribed rest depends on initial presentation after concussion. J Pediatr. 2017; 185:167-172. https://doi.org/10.1016/i.ipeds.2017.02.0 72.

30. Leddy JJ, Baker JG, Kozlowski K, Bisson L, Willer B. Reliability of a graded exercise test for assessing recovery from concussion. Clin $J$ Sport Med. 2011;21(2):89-94. https://doi.org/10.1097/ism.0b013e3181f $\mathrm{dc} 721$.

31. Quintana CG, B; Rockwood, HE; Heebner, NR; Johnson, AK; Ryan, KD; Mattacola CG. . Differences in head accelerations and physiological demand between live and Simulated professional horse racing. Comp Exerc Physiol. 2019

32. Haider MN, Leddy JJ, Wilber CG, et al. The predictive capacity of the Buffalo Concussion Treadmill Test after sport-related concussion in adolescents. Frontiers in neurology. $2019 ; 10: 395$.

https://doi.org/10.3389/fneur.2019.00395
33. Thomas D, Erdman K, Burke L. American College of Sports Medicine Joint Position Statement. Nutrition and Athletic Performance. Med Sci Sports Exerc. 2016;48(3):543-568. https://doi.org/10.1249/mss.0000000000 000852.

34. Alvares TS, Meirelles CM, Bhambhani YN, Paschoalin VM, Gomes PS. L-Arginine as a potential ergogenic aidin healthy subjects. Sports Me. 2011;41(3):233-248. https://doi.org/10.2165/11538590000000000-00000.

35. Leicht AS, Sinclair WH, Spinks WL. Effect of exercise mode on heart rate variability during steady state exercise. Eur J Appl Physiol. 2008;102(2):195-204. https://doi.org/10.1007/s00421-0070574-9.

36. Adams RP, Welch HG. Oxygen uptake, acidbase status, and performance with varied inspired oxygen fractions. J Appl Physiol. 1980;49(5):863-868.

https://doi.org/10.1152/iappl.1980.49.5.8 63.

37. Vox Media. Horse racing terminology. N.d. Accessed 2020.

https://www.anddownthestretchtheycome.co $\mathrm{m} /$ pages/horse-racing-terminology

38. McCrea $M$, Broglio $S$, McAllister $T$, et al. Return to play and risk of repeat concussion in collegiate football players: comparative analysis from the NCAA concussion study (1999-2001) and CARE consortium (20142017). Br J Sports Med. 2019:bjsports-2019100579. https://doi.org/10.1136/bjsports2019-100579.

39. Hutchison MG, Mainwaring L, Senthinathan A, Churchill N, Thomas S, Richards D. Psychological and physiological markers of stress in concussed athletes across recovery milestones. J Head Trauma Rehabil. 2016. https://doi.org/10.1097/htr.00000000000 00252.

40. Blake T, McKay C, Meeuwisse W, Emery C. The impact of concussion on cardiac autonomic function: A systematic review. Brain Inj. 2016;30(2):132-145. https://doi.org/10.3109/02699052.2015. 1093659. 